\title{
Predictors of enduring clinical distress in women with breast cancer
}

\author{
Deborah N. N. Lo-Fo-Wong' ${ }^{1}$ Hanneke C. J. M. de Haes ${ }^{1}$ - Neil K. Aaronson ${ }^{2}$. \\ Doris L. van Abbema ${ }^{3}$ - Mathilda D. den Boer ${ }^{4}$ - Marjan van Hezewijk ${ }^{5}$. \\ Marcelle Immink $^{6}$ - Ad A. Kaptein ${ }^{5}$ Marian B. E. Menke-Pluijmers ${ }^{7}$. \\ Anna K. L. Reyners ${ }^{8} \cdot$ Nicola S. Russell $^{2} \cdot$ Manon Schriek $^{9} \cdot$ Sieta Sijtsema $^{10}$ • \\ Geertjan van Tienhoven ${ }^{1} \cdot$ Mirjam A. G. Sprangers ${ }^{1}$
}

Received: 26 May 2016/Accepted: 2 July 2016/Published online: 14 July 2016

(C) The Author(s) 2016. This article is published with open access at Springerlink.com

\begin{abstract}
To date, little is known about enduring clinical distress as measured with the commonly used distress thermometer. We therefore used the distress thermometer to examine: (a) the prevalence of enduring clinical distress, distress-related problems, and subsequent wish for referral of women with breast cancer, and (b) sociodemographic, clinical, and psychosocial predictors of enduring clinical distress. The study had a multicenter, prospective, observational design. Patients with primary breast cancer completed a questionnaire at 6 and 15 months postdiagnosis. Medical data were retrieved from chart reviews. Enduring clinical distress was defined as heightened distress levels over time. The prevalence of enduring clinical distress, problems, and wish for referral was examined with descriptive analyses. Associations between predictors and enduring clinical distress were examined with multivariate analyses. One hundred sixty-four of 746 patients (22\%) reported having enduring clinical distress at 6 and 15 months postdiagnosis. Of these, $10 \%$ wanted to be
\end{abstract}

Deborah N. N. Lo-Fo-Wong

d.n.lo-fo-wong@amc.uva.nl

1 Department of Medical Psychology, Academic Medical Center, Meibergdreef 15, Amsterdam 1105 AZ, The Netherlands

2 The Netherlands Cancer Institute - Antoni van Leeuwenhoek Hospital, Plesmanlaan 121, 1066 CX Amsterdam, The Netherlands

3 GROW - School for Oncology and Developmental Biology, Maastricht University Medical Center, P. Debyelaan 25, 6229 HX Maastricht, The Netherlands

4 Erasmus MC - Cancer Institute, Groene Hilledijk 301, 3075 EA Rotterdam, The Netherlands

5 Leiden University Medical Center, Albinusdreef 2, 2333 ZA Leiden, The Netherlands referred for care. Fatigue was the most frequently reported problem by patients with and without clinical distress, at both time points. Lack of muscle strength $(\mathrm{OR}=1.82$, $95 \%$ CI 1.12-2.98), experience of a low level of life satisfaction (OR $=0.77,95 \%$ CI 0.67-0.89), more frequent cancer worry (OR $=1.40,95 \%$ CI $1.05-1.89$ ), and neuroticism $(\mathrm{OR}=1.09,95 \%$ CI $1.00-1.18)$ were predictors of enduring clinical distress. In conclusion, one in five women with breast cancer develops enduring clinical distress. Oncologists, nurse practitioners, and cancer nurses are advised to use single-item questions about distress and distress-related problems to ensure timely detection of high-risk patients. Providers should also routinely assess fatigue and its causes, as fatigue is the most frequently reported distress-related problem over time.

Keywords Distress - Referral - Breast cancer - Distress thermometer

6 Reinier de Graaf Hospital, Reinier de Graafweg 3-11, 2625 AD Delft, The Netherlands

7 Albert Schweitzer Hospital, Albert Schweitzerplaats 25, 3318 AT Dordrecht, The Netherlands

8 University of Groningen, University Medical Center Groningen, Hanzeplein 1, 9713 GZ Groningen, The Netherlands

9 St. Elisabeth Hospital, Hilvarenbeekseweg 60, 5022 GC Tilburg, The Netherlands

10 University Medical Center Utrecht, Heidelberglaan 100, 3584 CX Utrecht, The Netherlands 


\section{Introduction}

Coping with breast cancer, its treatment, and consequences can be stressful and, if not successful, can result in clinically relevant levels of psychological distress. Twenty-five to fifty percent of all cancer patients experience clinically relevant distress, which has been associated with lower treatment adherence, poorer clinical and psychosocial outcomes, and less satisfaction with medical care [1-6]. Breast cancer patients' distress levels may rise at different stages throughout the disease trajectory [7-11]. For example, some patients experience clinical distress just postdiagnosis, while others are mostly affected after treatment due to the discontinuation of regular contacts with medical specialists and/or to treatment-induced side effects [12, 13]. Fortunately, for most patients, distress levels tend to return to subclinical levels with time $[7,8,10,11,14,15]$. However, a subgroup of patients develops enduring, heightened, distress. Enduring clinical distress within 8 months after surgery predicts poorer psychosocial outcomes 6 years later [6]. Thus, clinicians and cancer nurses ought to be especially watchful of patients at risk for developing enduring distress.

In order to ensure timely detection, discussion, and treatment of distress, the National Comprehensive Cancer Center recommends use of an ultrashort screening tool, the Distress Thermometer, and accompanying Problem List [16]. This self-report questionnaire assesses cancer patients' distress level and distress-related problems, along with their wish for referral to professional care. The Distress Thermometer is currently used in various countries worldwide, including the United States, the United Kingdom, Japan, and China (see [17] for an overview). Given its common use, many oncologists and cancer nurses would benefit from knowing how many and which women with breast cancer are most likely to develop enduring clinical distress as measured with the Distress Thermometer. However, while a number of cross-sectional studies used the screening tool to examine distress among women with breast cancer [18-29], only one examined continuing distress, during the treatment phase [10]. Thus, more longitudinal research is needed.

In the present study we aimed to extend current insights using the Distress Thermometer to investigate which women are most likely to experience enduring distress after treatment for breast cancer. More specifically, enduring distress was defined as elevated distress levels at two points in time: 6 months postdiagnosis, around the completion of adjuvant therapy, and 9 months later, when women, generally, have reached the early survivorship phase [8]. We investigated the prevalence of enduring clinical distress, the prevalence of women's wish for referral, and sociodemographic, clinical, and psychosocial predictors of enduring clinical distress.

\section{Methods}

\section{Participants and design}

This study had a prospective, multicenter, observational design. Women with primary breast cancer who had been diagnosed up to 6 months earlier in one of nine hospitals in the Netherlands (i.e., six academic hospitals, two community hospitals, and one comprehensive cancer center) were eligible for the study, regardless of type of treatment. Patients were excluded if they were younger than 18 years, not literate in Dutch, or had a prognosis of 3 months or less. To minimize patient burden, participating centers could also exclude patients who were already participating in a concurrent study. Inclusion took place between March 2011 and 2013.

Participants completed a self-report questionnaire at two points in time: 6 months (time window 5-7 months) and 15 months (time window 14-16 months) postdiagnosis. Medical data were retrieved via chart reviews. Because the study was observational in nature, following Dutch regulations and guidelines regarding ethics review, it did not require formal review by the institutional review boards of the participating centers.

\section{Procedure}

Eligible patients with breast cancer were identified by their oncologist, nurse practitioner, or cancer nurse during a hospital visit. The health care provider informed the patient about the study and asked whether she would consider participation. The investigator subsequently invited interested patients to participate by e-mail or telephone. Participants could choose between a web-based questionnaire accessible through e-mail or a paper questionnaire sent by regular mail with a stamped return envelope. Formal agreement to participation involved signing an informed consent form. If necessary, patients received reminders after 2 and 4 weeks by e-mail or telephone.

\section{Outcome measures}

Psychosocial distress, distress-related problems, and wish for referral were assessed at both assessment points with the validated Dutch version of the Distress Thermometer, accompanied by the Problem List [16, 30, 31]. The Thermometer measures the level of distress in the past week with a single item (score $0-10)$. In the introduction to the 
questionnaire, we emphasized that it was a measure of distress related to breast cancer and its treatment. Based on the Dutch validation study [30] (see also [31]), a score of $\geq 5$ was used to identify women with clinically relevant levels of distress.

The Dutch version of the Problem List identifies 47 problems across the practical, family/social, emotional, religious/spiritual, and physical domains (response categories for the presence of each problem: yes/no). Wish for referral is assessed with one question. Patients are asked whether they would like to talk with a professional about their problems (response categories yes/maybe/no). In the current study, the response category 'not applicable' was added for patients who did not report any problems. We recoded the response categories to 'yes or maybe' versus 'no or not applicable' to enable comparability with other studies.

\section{Sociodemographic predictors}

Age at diagnosis, nationality, educational level, living situation, and employment status were assessed by self-report 6 months postdiagnosis.

\section{Clinical predictors}

Type of breast cancer, cancer stage (via pTNM-classification), types of treatments, and presence of recurrence (yes/ no) were retrieved from medical chart reviews. Previous use of psychosocial services (yes/no) and number of comorbid conditions (adapted from [32]) were assessed by self-report 6 months postdiagnosis.

\section{Psychosocial predictors}

We decided a priori to include the three most prevalent distress-related problems reported at 6 months postdiagnosis, as assessed with the previously described Problem List, as psychosocial predictors. In addition, social support, cancer worry, present life satisfaction, and neuroticism, as measured 6 months postdiagnosis, were included (variables selected on the basis of [8, 33-39]).

Social support was measured with the emotional/informational support subscale of the Medical Outcomes Study Social Support Survey (8 items, range 1 'support not available' to 5 'support always available', $\alpha=.96$ based on data from this study) [40, 41].

Life satisfaction was measured with a single item that asked patients about their present satisfaction with life as a whole (range 0-10) [42].

Frequency of cancer worry was assessed with a single item (range 1 'never' to 4 'always') (adapted from [43]).
Neuroticism was measured with a subscale of the Eysenck Personality Questionnaire (12 y/n items) [44, 45].

\section{Data analyses}

Prior to the main analyses, we first examined missing data patterns with separate variance $t$-tests, cross tabulations, a tabulated pattern table and Little's missing completely at random test with a $\chi^{2}$ statistic $(p<0.05)$. The results did not indicate substantial influence of the missing data on the results. Thus, we assumed that these data were missing at random. The percentage of missing values for all the variables ranged from $0 \%$ to $8 \%$. The data were subsequently multiple imputed by fully conditional specification with a maximum of five iterations [46, 47]. Secondly, we examined the correlations between distress and the psychosocial measures at 6 months postdiagnosis with Spearman's rank correlation coefficients [48] to ascertain the degree of interdependence. The correlations ranged from -0.15 for the correlation with social support to -0.52 for the correlation with life satisfaction, indicating low to moderate associations. We then proceeded to the main analyses.

The prevalence of enduring clinical distress, distress-related problems, and a wish for referral was examined with descriptive analyses. Associations between predictors and enduring clinical distress were investigated twice. We first performed univariate logistical regression analyses (significance level $p<0.10$ ), followed by a multivariate analysis with the predictors that were found to be significant in the univariate analyses (significance level for the multivariate analysis $p<0.05$ ). We then examined the associations again with Generalized Estimating Equations, taking into account the within-subject correlations. The same predictors were found to be significant in the multivariate analysis, with comparable parameters and standard errors. Therefore, only the results of the logistical regression analyses are reported, in odds ratios (OR). All of the analyses were conducted with SPSS version 21 for Windows.

\section{Results}

\section{Sample}

In total, 1353 women with breast cancer were assessed for study eligibility. Of these women, 1263 were eligible, and 1012 agreed to participate ( $80.1 \%$ of the eligible women). The current analyses were restricted to the 746 women who completed both the first and second questionnaires at 6 and 15 months postdiagnosis ( $73.7 \%$ of the participants) (see Fig. 1). The majority of the women was diagnosed with stage 1 or 2 invasive breast cancer, and was treated with lumpectomy and radiotherapy. Over $60 \%$ had one or more 
Fig. 1 Flowchart

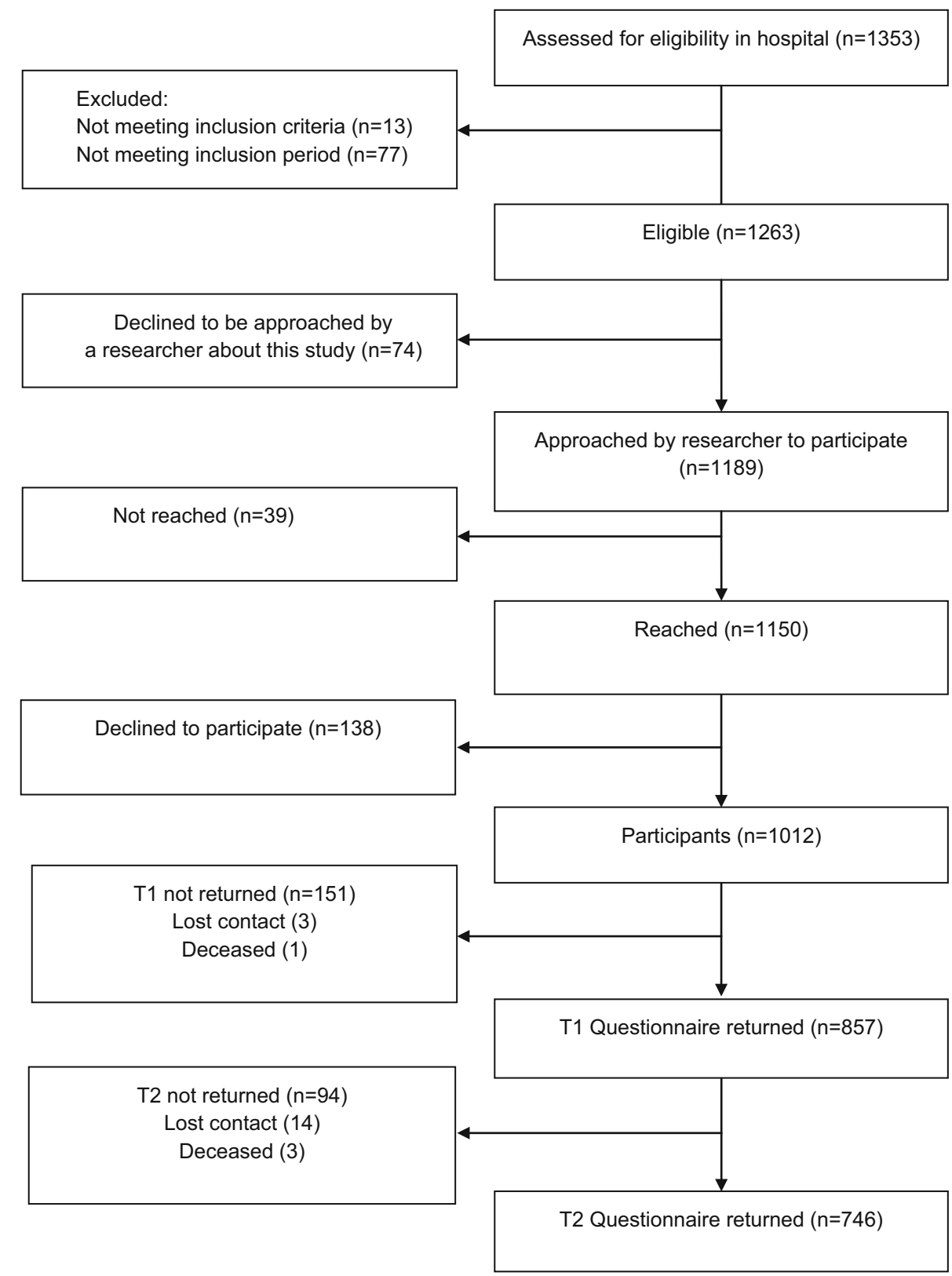

comorbid conditions (Table 1). Of the participants, $45.7 \%$ chose to receive a paper rather than a web-based questionnaire.

Participants did not differ significantly in age (groups based on median split, $p>0.10$ ) or cancer stage from nonrespondents, i.e., women who were approached by the researcher but who could not be reached, declined to participate, or who did not return both questionnaires $\left(\chi^{2}\right.$, $p>0.10)$. Furthermore, respondents who only completed the questionnaire at 6 months postdiagnosis $(n=111) \mathrm{did}$ not differ significantly in age $\left(\chi^{2}, p>0.10\right)$, cancer stage $\left(\chi^{2}, p>0.10\right)$, or distress scores $(t$-tests, $p>0.10)$ from the respondents who completed the questionnaires at both 6 and 15 months postdiagnosis $(n=746)$. We did not collect background data from patients who did not want to be approached about the study $(n=74)$.

\section{Prevalence of enduring clinical distress, distress- related problems, and wish for referral}

Forty-one percent of the patients experienced clinical distress 6 months postdiagnosis, and $32 \% 15$ months postdiagnosis. Twenty-two percent of the patients experienced enduring clinical distress at 6 and 15 months postdiagnosis (Table 2; Fig. 2). The most frequently reported problems 6 months postdiagnosis were fatigue, lack of physical fitness, lack of muscle strength, sleep problems, and concentration problems for both clinically and nonclinically 
Table 1 Sample Characteristics $(n=746)$

\begin{tabular}{|c|c|}
\hline Characteristics & Total sample \\
\hline \multicolumn{2}{|l|}{ Sociodemographic factors } \\
\hline Age at diagnosis (median, range) & $58(24-83)$ \\
\hline \multicolumn{2}{|l|}{ Nationality $(n, \%)$} \\
\hline Dutch only & $716(96.0)$ \\
\hline Dutch and other or other only & $30(4.0)$ \\
\hline \multicolumn{2}{|l|}{ Educational level $(n, \%)^{\mathrm{a}}$} \\
\hline Low & $346(46.4)$ \\
\hline Intermediate & $185(24.8)$ \\
\hline High & $215(28.8)$ \\
\hline \multicolumn{2}{|l|}{ Living situation $(n, \%)$} \\
\hline With partner & $383(51.3)$ \\
\hline With partner and child(ren) & $192(25.7)$ \\
\hline With child(ren) & $34(4.6)$ \\
\hline Alone & $127(17.0)$ \\
\hline Other & $10(1.3)$ \\
\hline \multicolumn{2}{|l|}{ Employment status $(n, \%)$} \\
\hline Paid work & $278(37.3)$ \\
\hline Homemaker & $141(18.9)$ \\
\hline Retired & $197(26.4)$ \\
\hline No work or unpaid & $56(7.5)$ \\
\hline (Partly) Work-disabled due to breast cancer & $74(9.9)$ \\
\hline \multicolumn{2}{|l|}{ Clinical factors } \\
\hline \multicolumn{2}{|l|}{ Type of breast cancer $(n, \%)$} \\
\hline Ductal carcinoma in situ (DCIS) & $104(13.9)$ \\
\hline Invasive and DCIS & $57(7.6)$ \\
\hline Invasive & $585(78.4)$ \\
\hline \multicolumn{2}{|l|}{ Cancer stage at diagnosis $(n, \%)$} \\
\hline TIS: carcinoma in situ & $104(13.9)$ \\
\hline Invasive early stage (T1/T2) & $621(83.2)$ \\
\hline Invasive late stage (T3/T4) & $21(2.8)$ \\
\hline \multicolumn{2}{|l|}{ Type of surgery $(n, \%)$} \\
\hline Lumpectomy & $630(84.5)$ \\
\hline Mastectomy & $105(14.1)$ \\
\hline Lumpectomy and mastectomy & $9(1.2)$ \\
\hline No lumpectomy or mastectomy & $2(0.3)$ \\
\hline \multicolumn{2}{|l|}{ Radio- and/or chemotherapy $(n, \%)$} \\
\hline Radiotherapy only & $470(63.0)$ \\
\hline Chemotherapy only & $24(3.2)$ \\
\hline Radio- and chemotherapy & $198(26.5)$ \\
\hline No radio- or chemotherapy & $54(7.2)$ \\
\hline \multicolumn{2}{|l|}{ Other types of treatment $(n, \% ;$ yes/no $)$} \\
\hline Hormonal & $258(34.6)$ \\
\hline Immunotherapy & $32(4.3)$ \\
\hline \multicolumn{2}{|l|}{ Recurrence $(n, \%)$} \\
\hline No & $731(98.0)$ \\
\hline Yes & $15(2.0)$ \\
\hline \multicolumn{2}{|l|}{ Previous use of psychosocial services $(n, \%)$} \\
\hline No & $578(77.5)$ \\
\hline
\end{tabular}

Table 1 continued

\begin{tabular}{lc}
\hline Characteristics & Total sample \\
\hline Yes & $168(22.5)$ \\
Comorbidity $(n, \%)$ & $282(37.8)$ \\
0 comorbid conditions & $231(31.0)$ \\
1 comorbid condition & $233(31.2)$ \\
2 or more comorbid conditions & \\
Psychosocial factors 6 months postdiagnosis & \\
Social support (median, range) & $7.25(1-5)$ \\
Life satisfaction (median, range) & $3(1-4)$ \\
Cancer worry (median, range) & $2(0-12)$ \\
Neuroticism (median, range) & \\
\hline
\end{tabular}

distressed patients. Fifteen months postdiagnosis fatigue, lack of physical fitness, and sleep problems were still most frequently reported (Table 3). Ten percent of the patients with enduring clinical distress had a wish for referral 15 months postdiagnosis. In addition, $17 \%$ of patients without enduring clinical distress also had a wish for referral (Table 4).

\section{Predictors of enduring clinical distress}

Of the sociodemographic factors, younger age $(\mathrm{OR}=0.96)$, living with a partner and children $(\mathrm{OR}=1.75)$ or only with children $(\mathrm{OR}=2.57)$, and having a paid job compared to being retired $(\mathrm{OR}=0.43)$ predicted enduring clinical distress in the univariate analyses $(p<0.10)$. Furthermore, having a mastectomy compared to a lumpectomy $(\mathrm{OR}=1.72)$, having chemotherapy $(\mathrm{OR}=2.47)$ or radioand chemotherapy $(\mathrm{OR}=1.85)$ compared to radiotherapy only, having received psychosocial services before the breast cancer diagnosis $(\mathrm{OR}=2.03)$, and having two or more comorbid conditions $(\mathrm{OR}=1.51)$ were significant clinical predictors of enduring clinical distress in these analyses. Additionally, all the seven psychosocial factors, namely fatigue $(\mathrm{OR}=4.81)$, lacking physical fitness $(\mathrm{OR}=3.12)$, lacking muscle strength $(\mathrm{OR}=4.16)$, experiencing a low level of social support $(\mathrm{OR}=0.75)$, a low level of life satisfaction $(\mathrm{OR}=0.60)$, more frequent cancer worry $(\mathrm{OR}=2.23)$, and more neuroticism $(\mathrm{OR}=1.23)$ were identified as univariate significant predictors of enduring clinical distress.

In the multivariate analysis lacking muscle strength $(\mathrm{OR}=1.82,95 \% \mathrm{CI} 1.12-2.98)$, experience of a low level of life satisfaction (OR $=0.77,95 \%$ CI $0.67-0.89)$, more frequent cancer worry $(\mathrm{OR}=1.40,95 \% \mathrm{CI}$ 1.05-1.89), and neuroticism ( $\mathrm{OR}=1.09,95 \% \mathrm{CI}$ 1.00-1.18) remained significant (Table 5). The variance explained $\left(R^{2}\right.$ Nagelkerke [49]) across imputed datasets was, on average, $30 \%$. 
Table 2 Prevalence of enduring clinical distress (score $\geq 5$ at both time points)

\begin{tabular}{lllll}
\hline & & \multicolumn{2}{l}{ Distress 15 months postdiagnosis $(n, \%)$} & \multicolumn{1}{c}{ Score $\geq 5$} \\
\cline { 3 - 4 } & & Score $<5$ & $74(9.9)$ & $461(59.1)$ \\
\hline Distress 6 months postdiagnosis $(n, \%)$ & Score $<5$ & $367(49.2)$ & $163(21.8)$ & $305(40.9)$ \\
Total & Score $\geq 5$ & $142(19.0)$ & $237(31.7)$ & $746(100.0)$ \\
\hline
\end{tabular}

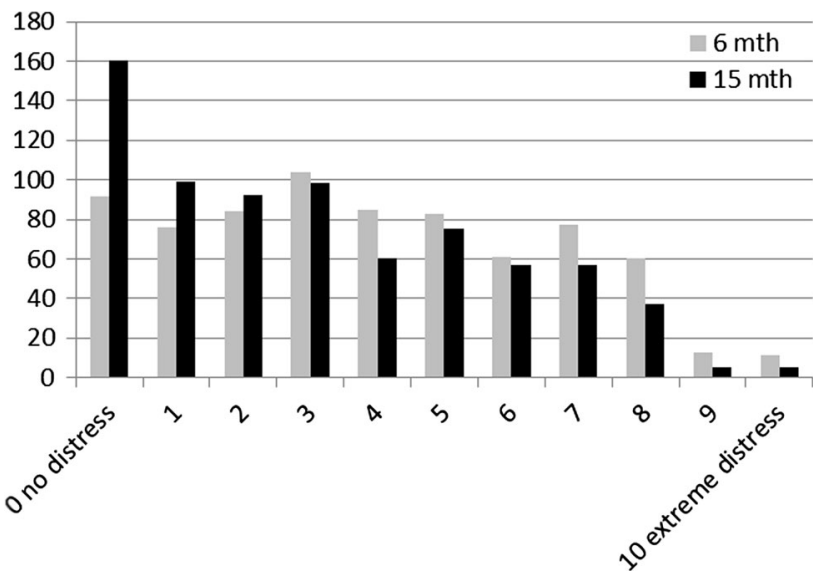

Fig. 2 Prevalence of distress 6 and 15 months postdiagnosis $(n=746)$

\section{Discussion}

While a number of studies have examined distress among women with breast cancer, insight into enduring distress, and predictors of enduring distress is still scarce, especially with regard to enduring distress as measured with the Distress Thermometer. In this longitudinal, nationwide, study we established that one in five patients with breast cancer reported clinical distress at 6 and 15 months postdiagnosis, as measured with the Distress Thermometer. Fatigue and lack of physical fitness were the most frequently reported problems at both time points. Ten percent of the participants with enduring clinical distress had a wish for referral.

The prevalence of distress in the only other, Danish, study that examined persistent distress with the Distress

Table 3 Top 10 distress-related problems 6 and 15 months postdiagnosis

\begin{tabular}{|c|c|c|c|c|c|c|c|c|}
\hline \multirow{3}{*}{$\begin{array}{l}\text { Rank } \\
1\end{array}$} & \multicolumn{4}{|l|}{6 months postdiagnosis } & \multicolumn{4}{|l|}{15 months postdiagnosis } \\
\hline & \multicolumn{2}{|l|}{ Distress score $<5(\%)$} & \multicolumn{2}{|l|}{ Distress score $\geq 5(\%)$} & \multicolumn{2}{|l|}{ Distress score $<5(\%)$} & \multicolumn{2}{|l|}{ Distress score $\geq 5(\%)$} \\
\hline & Fatigue & (33.2) & Fatigue & (35.3) & Fatigue & (28.3) & Fatigue & $(24.6)$ \\
\hline 2 & Lack of physical fitness & $(27.7)$ & Lack of physical fitness & $(33.5)$ & Lack of physical fitness & $(23.6)$ & Lack of physical fitness & $(22.3)$ \\
\hline 3 & $\begin{array}{l}\text { Lack of muscle } \\
\text { strength }\end{array}$ & $(18.6)$ & $\begin{array}{l}\text { Lack of muscle } \\
\text { strength }\end{array}$ & $(26.7)$ & Sleep problems & $(21.1)$ & Sleep problems & (19.7) \\
\hline 4 & Sleep problems & (18.3) & Sleep problems & $(24.8)$ & Memory problems & $(18.2)$ & $\begin{array}{l}\text { Concentration } \\
\text { problems }\end{array}$ & $(18.8)$ \\
\hline 5 & $\begin{array}{l}\text { Concentration } \\
\text { problems }\end{array}$ & (17.4) & $\begin{array}{l}\text { Concentration } \\
\text { problems }\end{array}$ & $(23.9)$ & $\begin{array}{l}\text { Concentration } \\
\text { problems }\end{array}$ & $(17.7)$ & Memory problems & $(18.4)$ \\
\hline 6 & Emotional control & $(16.1)$ & Housekeeping & $(22.3)$ & $\begin{array}{l}\text { Lack of muscle } \\
\text { strength }\end{array}$ & $(16.6)$ & $\begin{array}{l}\text { Lack of muscle } \\
\text { strength }\end{array}$ & $(18.4)$ \\
\hline 7 & Memory problems & $(15.7)$ & Emotional control & $(22.2)$ & Tingling in hands/feet & (14.9) & Emotional control & $(18.2)$ \\
\hline 8 & Tension/nervousness & (15.2) & Tension/nervousness & $(22.0)$ & Weight change & (14.8) & Tension/nervousness & $(18.0)$ \\
\hline 9 & Skin dry/itchy & (14.2) & Pain & $(21.1)$ & Emotional control & (14.5) & Pain & $(16.5)$ \\
\hline 10 & Weight change & (13.4) & Daily activities & (19.6) & Tension/nervousness & (13.8) & Fears & $(15.4)$ \\
\hline
\end{tabular}

Table 4 Prevalence of wish for referral

\begin{tabular}{llccc}
\hline & & \multicolumn{2}{l}{ Wish for referral 15 months postdiagnosis $(n, \%)$} & Total \\
\cline { 3 - 4 } & & No & Yes or maybe & \\
\hline Enduring clinical distress $(n, \%)$ & No & $456(61.1)$ & $127(17.0)$ & $583(78.2)$ \\
& Yes & $89(11.9)$ & $74(9.9)$ & $163(21.8)$ \\
Total & & $545(73.1)$ & $201(26.9)$ & $746(100.0)$ \\
\hline
\end{tabular}


Table 5 Predictors of enduring clinical distress

\begin{tabular}{ll}
\hline Predictor $^{\mathrm{a}}$ & Multivariate analysis \\
& OR $(95 \% \mathrm{CI})^{\mathrm{b}, \mathrm{c}}$
\end{tabular}

\begin{tabular}{ll}
\hline $\begin{array}{l}\text { Sociodemographic factors } \\
\text { Age at diagnosis }\end{array}$ & $0.99(0.96-1.03)$ \\
Living situation & \\
With partner & 1.00 (reference) \\
With partner and child(ren) & $1.33(0.72-2.43)$ \\
With child(dren) & $2.38(0.95-5.95)$ \\
Alone & $1.09(0.58-2.04)$ \\
Other & $2.58(0.44-15.24)$ \\
Employment status & \\
Paid work & $1.00($ reference) \\
Homemaker & $0.73(0.39-1.38)$ \\
Retired & $0.72(0.33-1.57)$ \\
No work or unpaid & $1.19(0.47-3.04)$ \\
(Partly) Work-disabled due to breast cancer & $0.69(0.31-1.55)$
\end{tabular}

Clinical factors

Type of surgery ${ }^{\mathrm{d}}$

Lumpectomy

Mastectomy

Lumpectomy and mastectomy

Radio- and or chemotherapy

Radiotherapy only

Chemotherapy only

Radio- and chemotherapy

No radio- or chemotherapy

Previous use of psychosocial services

No

Yes

Comorbidity

0 comorbid conditions

1 comorbid condition

2 or more comorbid conditions

Psychosocial factors

Fatigue

No

Yes

Lack of physical fitness

No

Yes

Lack of muscle strength

No

Yes

Social support

Life satisfaction

Cancer worry

Neuroticism

${ }^{a}$ Predictors are measured at 6 months postdiagnosis. Women with enduring distress are compared to those without enduring distress

${ }^{\mathrm{b}} \mathrm{OR}=$ odds ratio; $\mathrm{CI}=$ confidence interval

c Printed in bold: multivariate analysis $p<0.05$

${ }^{\mathrm{d}}$ Patients who did not receive surgery $(n=2)$ were excluded from the analyses
Thermometer was only $8 \%$ within the first 8 months postdiagnosis ( $n=323$ ) [10]. The lower prevalence in that study can be explained by the higher cut-off point of seven used. We found a comparable percentage $(7 \%)$ when we applied a cut-off point of seven to our data to enable comparison. The choice of a validated cut-off score depends on the purpose of screening [50], and this may differ between countries. In general, a higher score implies higher sensitivity but also a higher percentage of false negatives.

A remarkable finding was that the percentage of patients with a wish for referral in the group with enduring clinical distress was lower than in the group without enduring clinical distress (10 vs. $17 \%$ ). This is in contrast with the findings of previous, cross-sectional, studies that examined distress. The wish for a referral in these studies was, generally, more prevalent among women with a clinical level of distress than in women without distress (e.g., [21]). Our finding might indicate that a portion of the patients with enduring clinical distress has already been identified and referred through effective screening. Unfortunately, we did not assess use of psychosocial services up to 15 months, which would allow testing of this hypothesis.

Depending on service availability, all wishes for a referral deserve further inquiry. The high percentage of patients with enduring clinical distress without a wish for referral raises the question if and how a practitioner should proceed in that situation. Minimally, we would recommend that providers inform patients about the health risks associated with enduring clinical distress [6], and about those services that are available to manage and hopefully resolve such distress. Providers should also explore the patients' reason for their response. Some patients may already receive professional support or may prefer to deal with their distress on their own, perhaps with help from their informal network [51-54]. In the end, the wish to accept a referral is up to the patients. However, there may also be patients who misperceive their distress as not severe enough to ask for help, and who might accept help after being otherwise informed [53].

While younger age, having a partner, having less education, and having chemotherapy and not radiotherapy, were previously found to be associated with enduring clinical distress [10], none of these factors were significant predictors in our multivariate model. Based on our results, psychosocial variables appear more relevant than clinical variables to identify patients at risk of developing enduring clinical distress. Our analyses identified lack of muscle strength, a low level of life satisfaction, and more frequent cancer worry as significant predictors, independent of one's level of neuroticism (see also $[6,52]$ ). To our knowledge, this study is the first to demonstrate that these factors are of value in predicting enduring clinical distress of women 
with breast cancer. Based on our and previous findings, addition of cancer worry to future versions of the Problem List warrants further research attention (e.g., [55]; see also [37]).

Life satisfaction or happiness is increasingly recognized as a vital contributor to health, (partly) independent of negative affect (e.g., [56, 57]). It may be important to consider during the development of interventions to diminish distress. Some patients may prefer such a positive approach. A recent study demonstrated that the level of happiness experienced by breast cancer patients can, to a certain degree, be enhanced through intervention [35].

A study limitation is that we were not able to gather information about patients who declined to be approached for the study. Therefore, we could not establish our sample's representativeness in that regard. We did establish that there was no indication of a sample bias resulting from loss to follow-up. Another limitation is the large proportion of participants recruited at radiotherapy departments. As a consequence, patients with breast cancer who do not receive radiotherapy, though a minority, were underrepresented in our sample. To give an impression, a previous study based on data from a Dutch population-based, regional cancer registry, indicated that $17 \%$ of the women with breast cancer received systemic therapy without radiotherapy in the period 2002-2006 [58]. Finally, our study design did not allow us to make a distinction between women with breast cancer who experienced clinical distress continuously or intermittently, i.e., at the two assessment points only.

Strengths of the study are its large sample size, the prospective design, and the inclusion of psychosocial predictors that are easy to assess in clinical practice. We were able to use the Distress Thermometer to address two research topics that were recently identified as relevant in an ongoing debate about the usefulness and validity of screening for distress [59]. First, we investigated the occurrence of enduring clinical distress within a relevant time period [7, 11]. Second, we identified possible modifiable predictors of enduring clinical distress as targets for future interventions. While some of these predictors were previously found to be associated with distress, their importance in relation to predicting enduring distress had yet to be established. Furthermore, our study is the first to examine how many women with enduring distress would like a wish for a referral to professional care.

We recommend further studies of modifiable psychosocial factors in relation to resilience to distress over time in order to determine whether the occurrence of distress may be prevented even before its first manifestation $[7,8,14]$. We further suggest that patients' need for help in relation to distress be assessed more comprehensively than with the single question about a wish for referral. A substantial percentage of the patients who do not wish to talk to a professional, may consider use of other support services such as participating in an e-health intervention or support group. Finally, a large percentage of variance in our multivariate model remained unexplained. We recommend investigation of the influence of treatment center variables such as patient volume and waiting time before surgery as relevant predictors of breast cancer patients' distress, in addition to patient-based predictors. Treatment center variables might be important predictors of psychosocial outcomes [60].

In conclusion, one in five women with breast cancer experiences enduring clinical distress after treatment. In order to ensure timely detection of patients with enduring clinical distress, oncologists and cancer nurses are advised to pay special attention to distressed patients with a lack of muscle strength, as measured by the Distress Thermometer and Problem List. Fatigue is the most frequently reported problem over time, and thus should be routinely assessed and adequately addressed. Developers of distress interventions are advised to target these problems as well as life satisfaction and cancer worry in their program.

Acknowledgments We thank all care providers and researchers who contributed to this study. We especially thank Corry Marijnen (LUMC); Joyce Roijen, Annemie Courtens (MUMC); Sjane Olsthoorn (Erasmus MC Cancer Institute); Mary-Ann Thoms, Irma van Gelderen (Reinier de Graaf Hospital); Jan Anne Roukema (St. Elisabeth Hospital); Jolien Admiraal, Wieke Huisman-de Haan, Greetje Akerboom, Hennie Wilpstra-Dijkema, John Maduro (UMCG); Ingrid de Vries, Petra Duijveman, Marieke van de Grootevheen, Arjan van Hoorn, Sanne van Munster (UMCU); Pietje Muller, Susanne Kuiper (NKI-AVL); Kate Sitnikova, Jane van der Vloodt, Maha van der Plas, Linde Mollers, Anke Edink, Esmee van Vliet, Jeroen Gomes, Elvira Don, Rob van Os (AMC).

Funding This study was funded by Pink Ribbon, the Netherlands (Grant No. 2009.PS.C50).

\section{Compliance with ethical standards}

Conflict of interest The authors declare that they have no conflict of interest.

Ethical approval All procedures performed in studies involving human participants were in accordance with the ethical standards of the institutional and/or national research committee and with the 1964 Helsinki declaration and its later amendments or comparable ethical standards.

Informed consent Informed consent was obtained from all individual participants included in the study.

Open Access This article is distributed under the terms of the Creative Commons Attribution-NonCommercial 4.0 International License (http://creativecommons.org/licenses/by-nc/4.0/), which permits any noncommercial use, distribution, and reproduction in any medium, provided you give appropriate credit to the original author(s) and the source, provide a link to the Creative Commons license, and indicate if changes were made. 


\section{References}

1. Lebel S, Rosberger Z, Edgar L et al (2008) Predicting stressrelated problems in long-term breast cancer survivors. J Psychosom Res 65(6):513-523

2. Vitek L, Rosenzweig MQ, Stollings S (2007) Distress in patients with cancer: definition, assessment, and suggested interventions. Clin J Oncol Nurs 11(3):413-418

3. Fann JR, Thomas-Rich AM, Katon WJ et al (2008) Major depression after breast cancer: a review of epidemiology and treatment. Gen Hosp Psychiatr 30(2):112-126

4. Montazeri A (2008) Health-related quality of life in breast cancer patients: a bibliographic review of the literature from 1974 to 2007. J Exp Clin Cancer Res 27:32

5. Velikova G, Awad N, Coles-Gale R et al (2008) The clinical value of quality of life assessment in oncology practice-a qualitative study of patient and physician views. Psychooncology 17(7):690-698

6. Lam WW, Shing YT, Bonanno GA et al (2012) Distress trajectories at the first year diagnosis of breast cancer in relation to 6 years survivorship. Psychooncology 21(1):90-99

7. Helgeson VS, Snyder P, Seltman H (2004) Psychological and physical adjustment to breast cancer over 4 years: identifying distinct trajectories of change. Health Psychol 23(1):3-15

8. Henselmans I, Helgeson VS, Seltman H et al (2010) Identification and prediction of distress trajectories in the first year after a breast cancer diagnosis. Health Psychol 29(2):160-168

9. Liu JE, Wang HY, Wang ML et al (2014) Posttraumatic growth and psychological distress in Chinese early-stage breast cancer survivors: a longitudinal study. Psychooncology 23(4):437-443

10. Bidstrup PE, Christensen J, Mertz BG et al (2015) Trajectories of distress, anxiety, and depression among women with breast cancer: looking beyond the mean. Acta Oncol 54(5):789-796

11. Lester J, Crosthwaite K, Stout R et al (2015) Women with breast cancer: self-reported distress in early survivorship. Oncol Nurs Forum 42(1):E17-E23

12. Stanton AL, Ganz PA, Rowland JH et al (2005) Promoting adjustment after treatment for cancer. Cancer 104(11 Suppl):2608-2613

13. Jefford M, Mann GB, Nolte L et al (2014) Follow-up of women with early stage breast cancer. Curr Breast Cancer Rep 6:183-192

14. Lam WW, Bonanno GA, Mancini AD et al (2010) Trajectories of psychological distress among Chinese women diagnosed with breast cancer. Psychooncology 19(10):1044-1051

15. Bredart A, Merdy O, Sigal-Zafrani B et al (2016) Identifying trajectory clusters in breast cancer survivors' supportive care needs, psychosocial difficulties, and resources from the completion of primary treatment to 8 months later. Support Care Cancer 24(1):357-366

16. National Comprehensive Cancer Network (2014) NCCN clinical practice guidelines in oncology: Distress management V.1. Retrieved from http://www.nccn.org/professionals/physician_gls/ f_guidelines.asp\#supportive

17. Donovan KA, Grassi L, McGinty HL et al (2014) Validation of the distress thermometer worldwide: state of the science. Psychooncology 23(3):241-250

18. Luutonen S, Vahlberg T, Eloranta S et al (2011) Breast cancer patients receiving postoperative radiotherapy: distress, depressive symptoms and unmet needs of psychosocial support. Radiother Oncol 100(2):299-303

19. Mertz BG, Bistrup PE, Johansen C et al (2012) Psychological distress among women with newly diagnosed breast cancer. Eur $\mathbf{J}$ Oncol Nurs 16(4):439-443

20. Schubart JR, Emerich M, Farnan M et al (2014) Screening for Psychological Distress in Surgical Breast Cancer Patients. Ann Surg Oncol 21:3348-3353
21. Ploos van Amstel FK, van den Berg SW, van Laarhoven HW et al (2013) Distress screening remains important during follow-up after primary breast cancer treatment. Support Care Cancer 21(8):2107-2115

22. Agarwal J, Powers K, Pappas L et al (2013) Correlates of elevated distress thermometer scores in breast cancer patients. Support Care Cancer 21(8):2125-2136

23. Head BA, Schapmire TJ, Keeney CE et al (2012) Use of the Distress Thermometer to discern clinically relevant quality of life differences in women with breast cancer. Qual Life Res 21(2):215-223

24. Schaeffeler N, Pfeiffer K, Ringwald J et al (2015) Assessing the need for psychooncological support: screening instruments in combination with patients' subjective evaluation may define psychooncological pathways. Psychooncology 24(12):1784-1791

25. Denscherz CA, Hoffmann K, Lutz L et al (2013) Utilization and utility of psycho-oncologic support of patients with mammacarcinoma. Z Psychosom Med Psychother 59(4):369-377

26. Mosher CE, Duhamel KN (2012) An examination of distress, sleep, and fatigue in metastatic breast cancer patients. Psychooncology 21(1):100-107

27. Hegel MT, Moore CP, Collins ED et al (2006) Distress, psychiatric syndromes, and impairment of function in women with newly diagnosed breast cancer. Cancer 107(12):2924-2931

28. Iskandarsyah A, KC de, Suardi DR et al (2013) The Distress Thermometer and its validity: a first psychometric study in Indonesian women with breast cancer. PLoS One 8(2):e56353

29. Yong HW, Zubaidah J, Saidi M et al (2012) Validation of Malaysian translated distress thermometer with problem checklist among the breast cancer survivors in Malaysia. Asian J Psychiatr 5(1):38-42

30. Tuinman MA, Gazendam-Donofrio SM, Hoekstra-Weebers JE (2008) Screening and referral for psychosocial distress in oncologic practice: use of the Distress Thermometer. Cancer 113(4):870-878

31. Admiraal JM, Reyners AK, Hoekstra-Weebers JE (2013) Do cancer and treatment type affect distress? Psychooncology 22(8):1766-1773

32. Schoormans D, Sprangers MA, Pieper PG et al (2011) The perspective of patients with congenital heart disease: does health care meet their needs? Congenit Heart Dis 6(3):219-227

33. Alferi SM, Carver CS, Antoni MH et al (2001) An exploratory study of social support, distress, and life disruption among lowincome Hispanic women under treatment for early stage breast cancer. Health Psychol 20(1):41-46

34. Boinon D, Sultan S, Charles C et al (2014) Changes in psychological adjustment over the course of treatment for breast cancer: the predictive role of social sharing and social support. Psychooncology 23(3):291-298

35. Cerezo M, Ortiz-Tallo M, Cardenal V et al (2014) Positive psychology group intervention for breast cancer patients: a randomised trial. Psychol Rep 115(1):44-64

36. Bitsko MJ, Stern M, Dillon R et al (2008) Happiness and time perspective as potential mediators of quality of life and depression in adolescent cancer. Pediatr Blood Cancer 50(3):613-619

37. Soo H, Sherman KA (2015) Rumination, psychological distress and post-traumatic growth in women diagnosed with breast cancer. Psychooncology 24(1):70-79

38. Golden-Kreutz DM, Andersen BL (2004) Depressive symptoms after breast cancer surgery: relationships with global, cancer-related, and life event stress. Psychooncology 13(3):211-220

39. Den Oudsten BL, Van Heck GL, Van der Steeg AF et al (2009) Predictors of depressive symptoms 12 months after surgical treatment of early-stage breast cancer. Psychooncology 18(11):1230-1237 
40. Sherbourne CD, Stewart AL (1991) The MOS social support survey. Soc Sci Med 32(6):705-714

41. de Boer AG, Sprangers MA, Speelman HD et al (1999) Predictors of health care use in patients with Parkinson's disease: a longitudinal study. Mov Disord 14(5):772-779

42. Veenhoven R (n.d.) Measures of happiness, World database of happiness, Erasmus University Rotterdam, The Netherlands. Retrieved from: http://worlddatabaseofhappiness.eur.nl/hap_quer/hqi_fp.htm

43. McCaul KD, Goetz PW (2010) Worry. Retrieved from http:// cancercontrol.cancer.gov/brp/constructs/worry/worry.pdf

44. Eysenck HJ, Eysenck SBG (1991) Manual of the Eysenck Personality Scales (EPS Adult). Hodder \& Stoughton, London

45. Sanderman R, Arrindell WA, Ranchor AV et al [Measuring personality characteristics with the Eysenck Personality Questionnaire (EPQ). A Manual]. Groningen: Noordelijk Centrum voor Gezondheidsvraagstukken, Rijksuniversiteit Groningen

46. van Buuren S (2007) Multiple imputation of discrete and continuous data by fully conditional specification. Stat Methods Med Res 16(3):219-242

47. Azur MJ, Stuart EA, Frangakis C et al (2011) Multiple imputation by chained equations: what is it and how does it work? Int $\mathrm{J}$ Methods Psychiatr Res 20(1):40-49

48. Spearman C (1910) Correlation calculated from faulty data. Br J Psychol 3(3):271-295

49. Nagelkerke NJD (1991) A note on a general definition of the coefficient of determination. Biometrika 78:691-692

50. Bidstrup PE, Mertz BG, Dalton SO et al (2012) Accuracy of the Danish version of the 'Distress Thermometer'. Psychooncology 21(4):436-443

51. van Scheppingen C, Schroevers MJ, Smink A et al (2011) Does screening for distress efficiently uncover meetable unmet needs in cancer patients? Psychooncology 20(6):655-663
52. Schmid-Buchi S, Halfens RJ, Muller M et al (2013) Factors associated with supportive care needs of patients under treatment for breast cancer. Eur J Oncol Nurs 17(1):22-29

53. Clover K, Kelly P, Rogers K et al (2013) Predictors of desire for help in oncology outpatients reporting pain or distress. Psychooncology 22(7):1611-1617

54. Admiraal JM, van Nuenen FM, Burgerhof JG et al (2016) Cancer patients' referral wish: effects of distress, problems, socio-demographic and illness-related variables and social support sufficiency. Psychooncology. doi:10.1002/pon.4067

55. Deimling GT, Bowman KF, Sterns S et al (2006) Cancer-related health worries and psychological distress among older adult, long-term cancer survivors. Psychooncology 15(4):306-320

56. Steptoe A, Dockray S, Wardle J (2009) Positive affect and psychobiological processes relevant to health. J Pers 77(6):17471776

57. Pressman SD, Cohen S (2005) Does positive affect influence health? Psychol Bull 131(6):925-971

58. Sukel MP, van de Poll-Franse LV, Nieuwenhuijzen GA et al (2008) Substantial increase in the use of adjuvant systemic treatment for early stage breast cancer reflects changes in guidelines in the period 1990-2006 in the southeastern Netherlands. Eur J Cancer 44(13):1846-1854

59. Salmon P, Clark L, McGrath E et al (2015) Screening for psychological distress in cancer: renewing the research agenda. Psychooncology 24(3):262-268

60. Carey ML, Clinton-McHarg T, Sanson-Fisher RW et al (2011) Patient or treatment centre? Where are efforts invested to improve cancer patients' psychosocial outcomes? Eur J Cancer Care 20(2):152-162 